\title{
Avaliação da composição química de milho seco e armazenado em silo tipo alambrado com ar natural forçado
}

\author{
Evaluation of chemical composition of corn dried and stored with forced natural air
}

Luiz Carlos GUTKOSKI ${ }^{1 \star}$, Luiz EICHELBERGER ${ }^{2}$, João Anaracy SANTIN ${ }^{1}$, José Antônio PORTELLA², Franciela SPIER ${ }^{1}$, Rosana COLUSSI ${ }^{1}$

\begin{abstract}
Resumo
O trabalho objetivou estudar o efeito da umidade de colheita e do tempo de armazenamento em grãos de milho secos e armazenados em silos com ar natural forçado. Grãos de milho colhidos com 17,8; 18,9 e 20,5\% de água foram acondicionados em silos tipo alambrado com fundo falso perfurado e com ventiladores ligados ininterruptamente até a secagem. Amostras de milho foram coletadas nos tempos zero, 4, 8, 22 e 112 dias, em seis alturas de camada de cada silo (10, 60, 110, 160, 210 e $260 \mathrm{~cm}$ ). A composição química foi determinada pelo uso de Espectrofotômetro do Infravermelho Proximal (NIR) e os resultados expressos em porcentagem e em base seca. Os dados foram analisados estatisticamente (Anova) e nas interações significativas, elaborados os gráficos de regressão. Nas determinações de proteínas, lipídios, matéria seca e fibra em detergente neutro as interações foram significativas ao nível de $5 \%$ de probabilidade de erro, enquanto que em cinzas, umidade e carboidratos não foram verificadas diferenças significativas. A aeração natural forçada é capaz de reduzir a umidade do milho para $13 \%$, sendo tecnicamente viável em propriedades familiares.
\end{abstract}

Palavras-chave: Zea mays; pós-colheita; qualidade industrial; NIR.

\begin{abstract}
The aim of this work was to study the effects of moisture at harvest and time of storage upon grains of corn dried and stored in bins with forced natural air. Grains of corn harvested with $17.8 ; 18.9$, and $20.5 \%$ of water were stored in drying bins with false floor with fans working full-time until drying. Samples of corn were collected at zero, 4, 8, 22, and 112 days from six different heights in each bin (10, 60, 110, 160, 210 and $260 \mathrm{~cm}$ ). The chemical composition was determined through Near-Infrared Spectrophotometer (NIR) and the results were expressed in percentage at dry basis. The data were statistically analyzed (Anova) and for the significant interactions graphics of regression were provided. In the process of determination of protein, fat, dry matter, and neutral detergent fiber the interactions were significant at $5 \%$ error probability, whereas in ash, moisture and carbohydrates no significant difference was observed. Forced natural air is able to reduce corn moisture up to $13 \%$, thus it is technically feasible in familiar properties.
\end{abstract}

Keywords: Zea mays; post-harvest; industrial quality; NIR.

\section{Introdução}

A secagem é o processo físico de remoção parcial de água, envolvendo duas fases simultâneas que são o transporte do vapor de água da superfície do grão para o ar e movimento de água do interior para a superfície do grão (BROOKER; BAKKER-ARKEMA; HALL, 1992; BIAGI; BERTOL; CARNEIRO, 2002). O fluxo de ar é fundamental no processo, pois juntamente com temperatura do ar e movimento da massa de grãos, determinam a velocidade de secagem (SILVA, 2000). O que limita o uso de altas temperaturas na secagem são as consequências sobre as características tecnológicas dos grãos.

Temperatura elevada conduz a alta taxa de evaporação da água na superfície dos grãos, aumentando o gradiente de umidade do interior para a periferia. Isso gera tensões internas que provocam danos mecânicos por trincamento (ALVES et al., 2001) e aumentam a suscetibilidade à quebra dos grãos permitindo a contaminação por microrganismos toxigênicos (TANAKA et al., 2001; DENTI; REIS, 2003). Além disso, temperatura elevada causa alterações nos constituintes químicos dos grãos, como lipídios, carboidratos e proteínas (CARVALHO et al., 2004).

Secadores são equipamentos utilizados para a redução do teor de água dos grãos, condição essencial para que possam ser armazenados até o consumo ou industrialização. No armazenamento, a qualidade dos grãos deve ser preservada, tendo em vista a ocorrência de alterações físicas, químicas e microbiológicas. A velocidade e a intensidade desses processos dependem da qualidade dos grãos, do sistema de armazenagem utilizado e dos fatores ambientais (ELIAS et al., 2007).

A aeração é utilizada para modificar o microclima da massa de grãos armazenados, tornando-o desfavorável ao

\footnotetext{
Recebido para publicação em 25/2/2008

Aceito para publicação em 4/1/2009 (003231)

${ }^{1}$ Centro de Pesquisa em Alimentação, Universidade de Passo Fundo - UPF, CP 611, CEP 99001-970, Km 171, BR 285, São José, Passo Fundo - RS, Brasil,

E-mails: gutkoski@upf.br,santin@upf.br,franciela@ibest.com.br,rosana_colussi@yahoo.com.br

${ }^{2}$ Embrapa Trigo, Rodovia BR 285, Km 294, CP 451, CEP 99001-970, Passo Fundo-RS, Brasil, E-mails: luizei@cnpt.embrapa.br, japortella@upf.br

${ }^{*}$ A quem a correspondência deve ser enviada
} 
desenvolvimento de microrganismos e, ao mesmo tempo, criar condições favoráveis à conservação prolongada dos grãos (FARONI; DEVILLA, 2001). A aeração permite resfriar os grãos ou mantê-los frios. O resfriamento dos grãos em até $8{ }^{\circ} \mathrm{C}$ nas regiões temperadas e de 15 a $17^{\circ} \mathrm{C}$ nas subtropicais é suficiente para deter a proliferação de insetos e limitar a contaminação por fungos (PORTELLA; EICHELBERGER, 2001). Quando a aeração é empregada na retirada de água dos grãos, o processo é lento e dependente das condições psicrométricas do ar (SILVA, 2000).

Rodriguez (1993) utilizou aeração para secagem de milho com $18 \%$ de umidade para $13,8 \%$, concluindo que os grãos não sofreram deterioração durante a secagem, inclusive no que se refere ao seu poder germinativo e que o sistema é altamente eficiente energeticamente. No entanto, o custo operacional foi elevado. A utilização de fonte suplementar de calor na secagem por ar forçado tem a função de baixar a umidade relativa do ar, reduzindo o tempo (ELIAS et al., 2007).

A redução nos conteúdos de lipídios, carboidratos, proteínas e vitaminas durante o período de armazenamento, resultam em perdas de material orgânico, do peso volumétrico, da matéria seca, bem como do valor comercial e nutricional do milho (FLEURAT-LESSARD, 2002). Os lipídios são os constituintes mais suscetíveis à degradação química e influenciam diretamente na secagem e conservabilidade do produto armazenado (RUPOLLO et al., 2004). A degradação dos lipídios, com o consequente aumento de acidez graxa pode conduzir à formação de odor e sabor indesejáveis, influenciando, negativamente, a qualidade nutricional e sensorial do produto armazenado (WEBER; ELIAS; GUTKOSKI, 2002). A velocidade das alterações dos lipídios depende da umidade, da temperatura e do tempo de armazenamento do milho (BIAGGIONI; SOARES; FERREIRA, 2005).

Este trabalho foi desenvolvido com o objetivo de estudar o efeito da umidade de colheita e do período de armazenamento em grãos de milho secos pelo emprego da aeração natural forçada em equipamentos nos quais permaneçam armazenados até o beneficiamento.

\section{Material e métodos}

\subsection{Material}

O trabalho foi realizado no Centro de Extensão e Pesquisas Agropecuárias (Cepagro) da Universidade de Passo Fundo (UPF), nos laboratórios do Centro de Pesquisa em Alimentação (Cepa) da UPF e no laboratório de Análise de Sementes da Embrapa Trigo, Passo Fundo, RS.

Nos experimentos foram utilizados grãos de milho (Zea mays L) do híbrido simples Pioneer 32R21, semeado em três épocas espaçadas em 10 dias, sendo a primeira semeadura realizada em 30 de setembro de 2005. A colheita foi realizada por colhedora John Deere 1165 e os grãos acondicionados, sem prélimpeza, em silos especialmente construídos para o projeto.

Os grãos de milho foram acondicionados em silos do tipo alambrado com fundo falso perfurado, e com diâmetro de 1,5 m e altura de 3,2 m, construídos sobre plenum de concreto, cada qual equipado com ventilador acionado por motor elétrico de 1,5 HP, gerando fluxo de ar de $4,0 \mathrm{~m}^{3} / \mathrm{min} / \mathrm{t}$ com o silo cheio. Em cada silo foram acondicionados $4.200 \mathrm{~kg}$ de grãos de milho oriundos de cada época de semeadura, sem pré-limpeza e com grau de umidade de 20,5\% (Silo A), 18,9\% (Silo B) e $17,8 \%$ (Silo C). Cada silo foi dividido longitudinalmente em três partes, representando as repetições do tratamento. Os ventiladores foram ligados ininterruptamente até 14 dias e, depois desse período, somente durante o dia e sem a ocorrência de chuva. A secagem foi encerrada quando o grau de umidade de $13 \%$ da frente de secagem atingiu a superfície da massa de grãos. As condições de temperatura e de umidade relativa do ar ambiente foram monitoradas através da Estação Meteorológica da Embrapa Trigo durante o período de secagem de milho.

\subsection{Preparo de amostras}

As amostras foram coletadas periodicamente em seis camadas internas de cada silo $(10,60,110,160,210$ e $260 \mathrm{~cm}$ de altura, respectivamente), na quantidade de 1,0 kg de grãos, acondicionadas em embalagens de algodão e as avaliações, realizadas imediatamente após a colheita (tempo zero) e aos 4 , 8, 22 e 112 dias de secagem e armazenamento.

As amostras de milho foram moídas em moinho de facas marca Knifetec, em granulometria inferior a $0,5 \mathrm{~mm}$, identificadas e colocadas em embalagens de vidro hermeticamente fechadas.

\subsection{Análises}

\section{Umidade}

A perda de água dos grãos de milho durante os períodos de secagem e armazenamento foi determinada pelo emprego de estufa regulada a $105 \pm 3{ }^{\circ} \mathrm{C}$, com circulação de ar por 24 horas, realizado em duplicada e em acordo com a metodologia de análise de sementes preconizada pelo Ministério da Agricultura, Pecuária e Abastecimento (BRASIL, 1992).

\section{Composição química}

As determinações de matéria seca e dos constituintes umidade, proteína bruta, lipídios, minerais, carboidratos e fibra detergente neutro foram realizadas pelo emprego do Espectrômetro do Infravermelho Proximal (NIR), marca Perstorp Analytical, modelo 5000 do Centro de Pesquisa em Alimentação (Cepa) da Universidade de Passo Fundo (UPF). Os constituintes químicos foram obtidos a partir da utilização da curva de calibração Fartan do NIR, construída pelo laboratório de Físico-Química do Cepa a partir de métodos oficiais recomendados pela AOAC (2005). Os resultados das leituras realizadas em duplicata foram expressos em porcentagem e em base seca. Para obter o valor de proteína bruta foi utilizado o fator 6,25 . 


\subsection{Delineamento experimental e análise estatística}

O experimento foi conduzido em delineamento inteiramente casualizado em arranjo fatorial $3 \times 6 \times 5$, ou seja, três teores de água $(20,5 ; 18,9$ e $17,8 \%)$, seis alturas de camada $(10,60,110$, 160,210 e $260 \mathrm{~cm}$ ) e cinco períodos de armazenamento (0, 4, $8,22,112$ dias). Os resultados foram submetidos à análise de variância (Anova) e nos modelos significativos pelo teste $F$ de alturas de camada, elaboradas as equações de regressão linear ou quadrática. As análises e os gráficos das equações de regressão foram elaborados com o auxílio do programa estatístico Microsoft Excel ${ }^{\oplus}$, no modo estatístico.

\section{Resultados e discussão}

Os dados meteorológicos de precipitação, temperatura média e umidade relativa do ar média (UR), coletados durante o período de secagem dos grãos de milho estão representados na Figura 1. Nos primeiros cinco dias não houve precipitação e a UR permaneceu abaixo de $60 \%$. Nos 12 dias seguintes ocorreram precipitações intercaladas, período em que a UR se manteve ligeiramente acima de $80 \%$. No final do período de secagem não ocorreram precipitações pluviométricas ou estas foram de baixa intensidade. A temperatura média do ar se manteve elevada nos primeiros 12 dias (em torno de $23^{\circ} \mathrm{C}$ ), baixando para cerca de $19{ }^{\circ} \mathrm{C}$ até o final do período de secagem, o que pode ser considerado comportamento normal para a estação de outono no sul do Brasil. As elevadas temperaturas do ar, no início da secagem, associadas à ausência de precipitação pluviométrica proporcionaram a manutenção da UR em valores mais baixos no início do período de secagem, se elevando com a redução da temperatura média do ar e a ocorrência de chuvas.

Independentemente da umidade de colheita e da altura de camada interna dos silos, observou-se decréscimo da umidade dos grãos com o aumento do tempo de secagem (Tabela 1). Os silos A (20,5\% de água), B (18,9\% de água) e C (17,8\% de água)

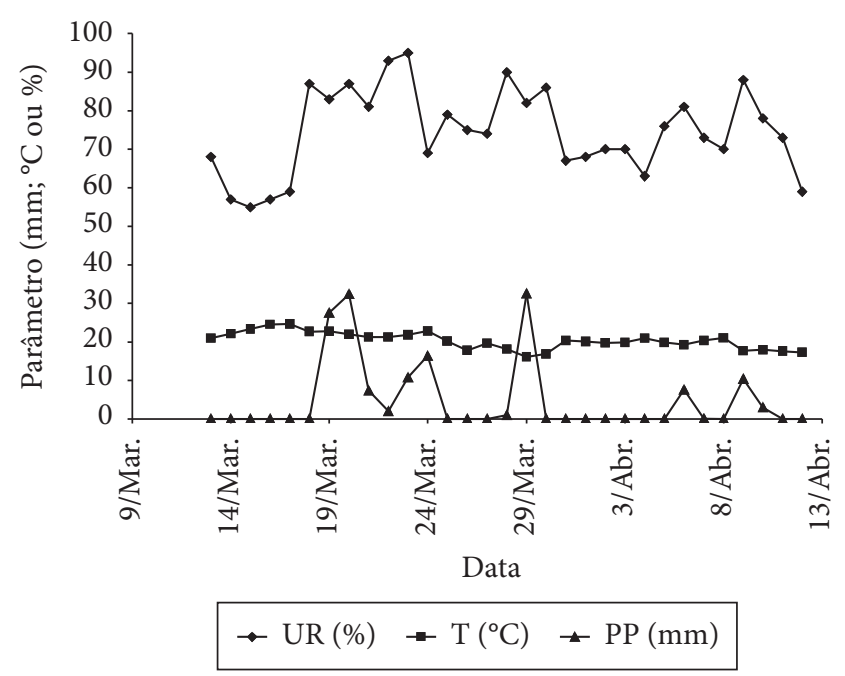

Figura 1. Precipitação (PP), temperatura média (T) e umidade relativa do ar (UR) medidas durante o período de secagem de grãos de milho em silos tipo alambrado com ar natural forçado. apresentaram 12,8; 12,5 e 13,0\% de água ao final de 488 horas, 435 horas e 420 horas de aeração, respectivamente. Portella e Eichelberger (2001), em estudo do emprego de gás liquefeito de petróleo na secagem estacionária de milho com ar aquecido, verificaram que na colheita com 35, 25 e 18\% de água o aumento da temperatura de secagem de 40 para $70{ }^{\circ} \mathrm{C}$ diminuiu o tempo de secagem à metade, enquanto que, com o aumento de 70 para $100{ }^{\circ} \mathrm{C}$, o tempo de secagem diminuiu em $28 \%$. Esses dados mostram que a taxa de transporte interno da água, do interior do grão para a superfície, onde ocorre troca com o ar, é limitante do processo de secagem, e o aumento de temperatura do ar não resultou no aumento proporcional na velocidade de secagem. A duração do tempo de secagem realizada a $40{ }^{\circ} \mathrm{C}$ foi de 11,4 e 7,7 horas para milho colhido com 25 e 18\% de água, respectivamente.

Os efeitos das interações de tempo de secagem e altura de camada, de tempo de secagem e umidade de colheita e de altura de camada e umidade de colheita sobre os teores de proteínas, lipídios, matéria seca e fibra detergente neutro foram significativos, enquanto que nas determinações de umidade, carboidratos e cinzas não diferiram significativamente entre si (Tabela 2).

No decorrer do período de armazenamento ocorreu um acréscimo no teor de proteínas para as três umidades de colheita (Figura 2). O teor de água de colheita não interferiu na variação do conteúdo proteico dos grãos de milho armazenados secos em silo alambrado e armazenados por 112 dias.

Bhattacharya e Raha (2002) afirmam que a proteína bruta serve como fonte preliminar de carbono e nitrogênio para o crescimento e o metabolismo dos fungos. A perda no teor de proteínas durante a fase adiantada de incubação indica proteólise e a formação de compostos mais simples como aminoácidos, que são utilizados como fonte de nutrientes pelos fungos. Os autores verificaram que o conteúdo de proteína bruta apresentou tendência de aumento em grãos de milho armazenado por 12 meses. Este aumento foi devido à formação de proteína fúngica, a qual não foi separada, sendo quantificada juntamente com a proteína bruta do grão. Assim, o conteúdo determinado representou a soma total da proteína do grão mais a da proteína fúngica.

Neste trabalho, as equações de regressão significativas para teor proteico do silo A foram as alturas de camada 60,210 e $260 \mathrm{~cm}$, com coeficientes de determinação $\left(\mathrm{R}^{2}\right)$ acima de 0,77 , indicando que podem ser utilizadas para predizer o comportamento deste constituinte no período de armazenamento estudado. Para o silo B, foram significativas as

Tabela 1. Umidade inicial, umidade final e tempo de secagem de grãos de milho em silos tipo alambrado com ar natural forçado.

\begin{tabular}{cccc}
\hline $\begin{array}{c}\text { Silo tipo } \\
\text { alambrado }\end{array}$ & $\begin{array}{c}\text { Umidade } \\
\text { inicial (\%) }\end{array}$ & $\begin{array}{c}\text { Umidade } \\
\text { final (\%) }\end{array}$ & $\begin{array}{c}\text { Tempo de } \\
\text { secagem (horas) }\end{array}$ \\
\hline Silo A & 20,5 & 12,8 & 488 \\
Silo B & 18,9 & 12,5 & 439 \\
Silo C & 17,8 & 13,0 & 420 \\
\hline
\end{tabular}


Tabela 2. Análise de variância e teste $F$ de umidade (U), proteínas (Prot), lipídios (Lip), matéria seca (MS), fibra detergente neutro (FDN), carboidratos (Carb) e cinzas de milho em seis alturas de camada $(10,60,110,160,210$ e $260 \mathrm{~cm})$ nos silos A, B e C com umidade de colheita de $20,5,18,9$ e 17,8\%, respectivamente, e submetidos à secagem e armazenamento com ar natural forçado.

\begin{tabular}{|c|c|c|c|c|c|c|c|c|}
\hline \multirow[t]{2}{*}{ Fonte de variação } & \multirow[t]{2}{*}{ G.L. } & $\mathrm{U}$ & Prot & Lip & MS & FDN & Carb & Cinzas \\
\hline & & $\mathrm{P}>\mathrm{F}$ & $\mathrm{P}>\mathrm{F}$ & $\mathrm{P}>\mathrm{F}$ & $\mathrm{P}>\mathrm{F}$ & $\mathrm{P}>\mathrm{F}$ & $\mathrm{P}>\mathrm{F}$ & $\mathrm{P}>\mathrm{F}$ \\
\hline Silo $^{(1)}$ & 2 & $0,40^{\text {ns }}$ & $0,02^{*}$ & $0,15^{\mathrm{ns}}$ & $0,86^{\mathrm{ns}}$ & $0,01^{\star *}$ & $0,45^{\mathrm{ns}}$ & $0,49^{\text {ns }}$ \\
\hline $\mathrm{Tempo}^{(2)}$ & 4 & $0,02^{*}$ & $0,00^{* *}$ & $0,00^{* *}$ & $0,00^{* *}$ & $0,01^{\star *}$ & $0,34^{\mathrm{ns}}$ & $0,47^{\text {ns }}$ \\
\hline Camada $^{(3)}$ & 5 & $0,45^{\mathrm{ns}}$ & $0,16^{\mathrm{ns}}$ & $0,15^{\mathrm{ns}}$ & $0,00^{* *}$ & $0,04^{*}$ & $0,49^{\text {ns }}$ & $0,49^{\text {ns }}$ \\
\hline Silo $^{\star}$ tempo $^{(4)}$ & 8 & $0,39^{\text {ns }}$ & $0,02^{\star}$ & $0,02^{\star}$ & $0,00^{* *}$ & $0,00^{* *}$ & $0,37^{\mathrm{ns}}$ & $0,44^{\mathrm{ns}}$ \\
\hline Silo $^{*}$ camada $^{(4)}$ & 10 & $0,22^{\mathrm{ns}}$ & $0,00^{* *}$ & $0,00^{* *}$ & $0,00^{* *}$ & $0,00^{* *}$ & $0,34^{\mathrm{ns}}$ & $0,43^{\text {ns }}$ \\
\hline Tempo $^{\star}$ camada $^{(4)}$ & 20 & $0,15^{\mathrm{ns}}$ & $0,00^{* *}$ & $0,00^{* *}$ & $0,00^{* *}$ & $0,00^{* *}$ & $0,70^{\text {ns }}$ & $0,50^{\text {ns }}$ \\
\hline Silo $^{\star}$ tempo $^{\star}$ camada $^{(4)}$ & 40 & $0,59^{\text {ns }}$ & $0,00^{* *}$ & $0,00^{* *}$ & $0,00^{* *}$ & $0,00^{* *}$ & $0,30^{\mathrm{ns}}$ & $0,47^{\text {ns }}$ \\
\hline $\mathrm{CV}^{(1)}(\%)$ & - & 7,32 & 1,32 & 3,08 & 0,16 & 1,87 & 6,33 & 155,42 \\
\hline $\mathrm{CV}^{(2)}(\%)$ & - & 7,55 & 1,08 & 1,72 & 0,29 & 2,85 & 6,46 & 149,52 \\
\hline $\mathrm{CV}^{(3)}(\%)$ & - & 7,86 & 2,32 & 4,58 & 0,29 & 3,38 & 5,79 & 148,04 \\
\hline $\mathrm{CV}^{(4)}(\%)$ & - & 7,53 & 2,07 & 4,75 & 0,26 & 4,13 & 6,02 & 148,73 \\
\hline Média & - & 12,88 & 10,53 & 4,45 & 87,03 & 8,42 & 74,85 & 1,58 \\
\hline
\end{tabular}

${ }^{1}$ Significativo ao nível de $5 \%$ de probabilidade ${ }^{\star}(\mathrm{p} \leq 0,05)$ e $1 \%$ de probabilidade ${ }^{\star \star}(\mathrm{p} \leq 0,01) ; \mathrm{e}^{2} \mathrm{~ns}$ - não significativo ao nível de $5 \%$ de probabilidade $(\mathrm{p}>0,05)$.

Silo A
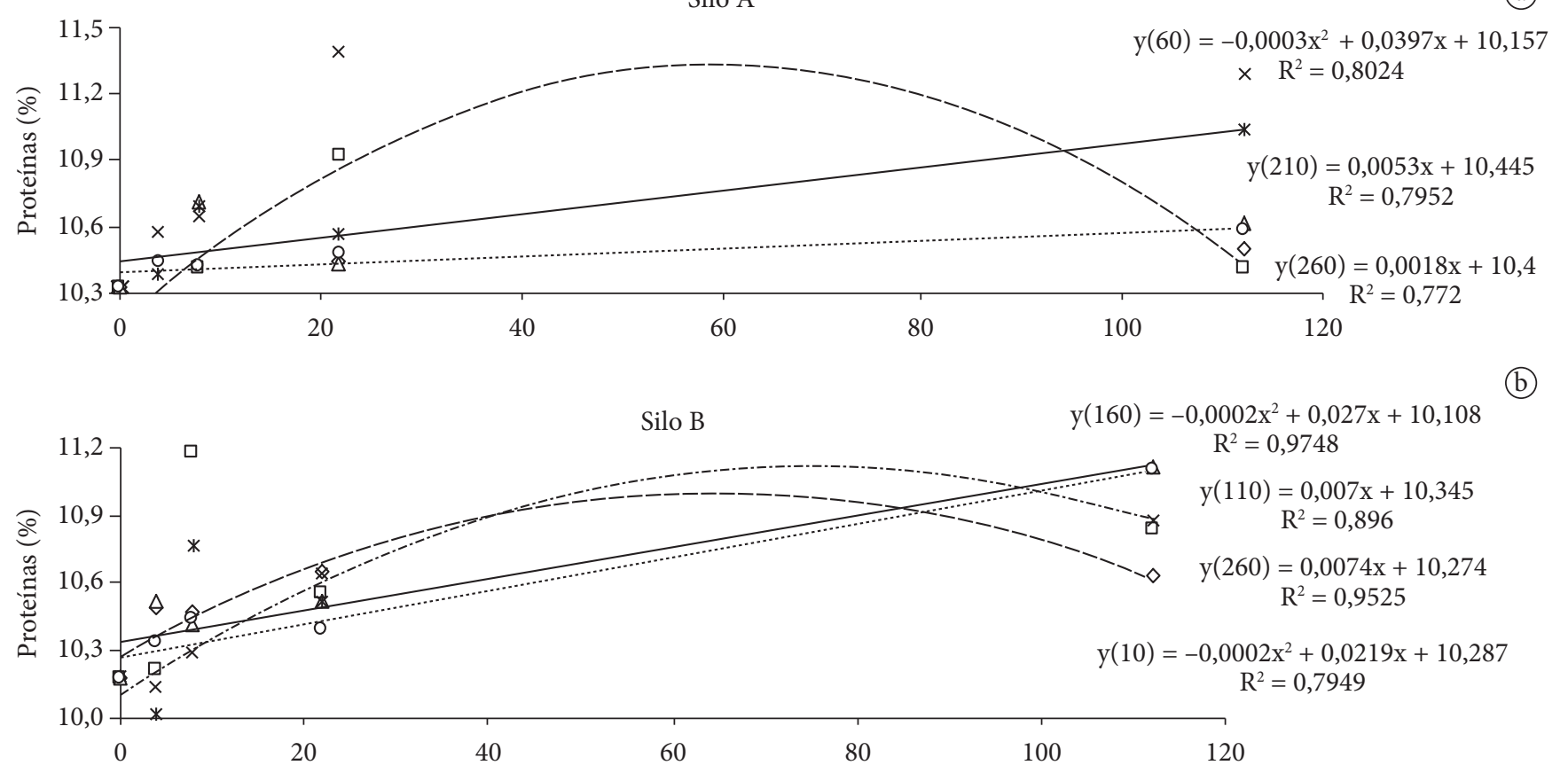

(b)

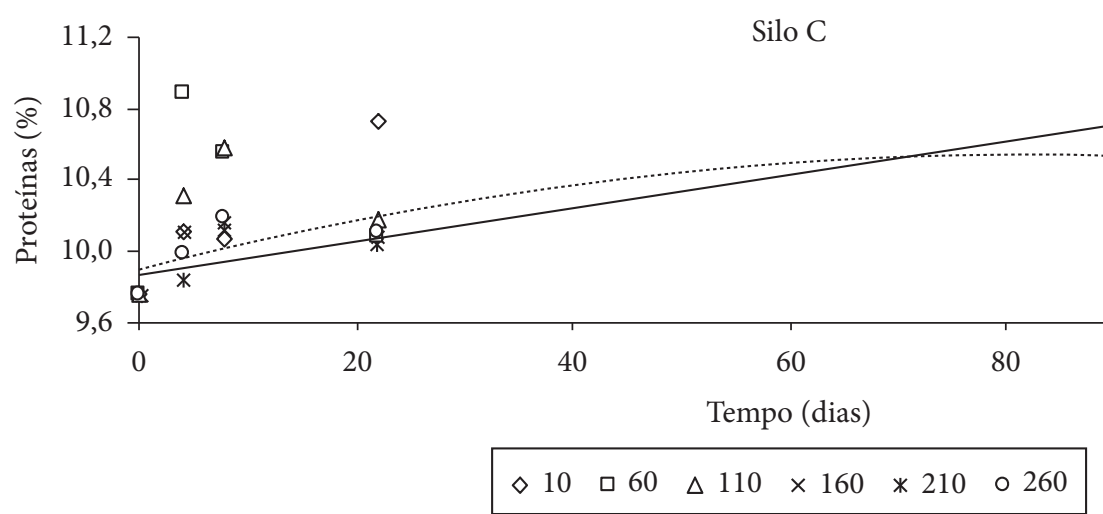

Figura 2. Teor de proteínas de seis alturas de camada (10,60, 110, 160, 210 e $260 \mathrm{~cm})$ nos silos A, B e C contendo grãos de milho colhidos com 20,5; 18,9 e 17,8\% de água, respectivamente, e submetidos à secagem e armazenamento com ar natural forçado. 
equações 10, 110, 160 e $260 \mathrm{~cm}$ de altura de camada, com melhor ajuste para a de $160 \mathrm{~cm}$, com coeficiente de determinação $\left(\mathrm{R}^{2}\right)$ de 0,975 . Para o silo $C$, foram significativas as equações 210 e $260 \mathrm{~cm}$. A análise destes resultados mostrou que as variações significativas de proteínas ocorreram no milho armazenado na parte superior dos silos, e o aumento não dependeu da umidade inicial de colheita.

Na parte superior dos silos, a secagem foi mais lenta, o que pode ter propiciado maior metabolismo dos grãos e o maior desenvolvimento fúngico, estando os resultados em acordo com os relatados por Bhattacharya e Raha (2002).

Observa-se que houve redução no teor de lipídios durante o período de armazenamento (Figura 3). Para Rupollo et al. (2004), o aumento do índice de acidez foi proporcional à umidade inicial dos grãos armazenados nos sistemas hermético e convencional e, apesar de a temperatura do ar de secagem ter afetado de forma significativa a atividade residual das enzimas lipase e peroxidase, esta redução não foi suficiente para impedir a degradação de lipídios. O aumento de ácidos graxos livres dos lipídios ocorre através da ação de enzimas lipase, peroxidase e fosfolipases presentes no próprio grão ou produzidas pela microflora associada (ZADERNOWSKI; POLAKOWSKA; RASHED, 1999).

No presente trabalho, a redução do teor de lipídios foi inferior a $10 \%$ no período de 120 dias de armazenamento. No silo com maior umidade inicial de armazenamento (A), observou-se o efeito de camada na redução do teor de lipídios em milho, ocorrendo declínio significativo com a elevação da
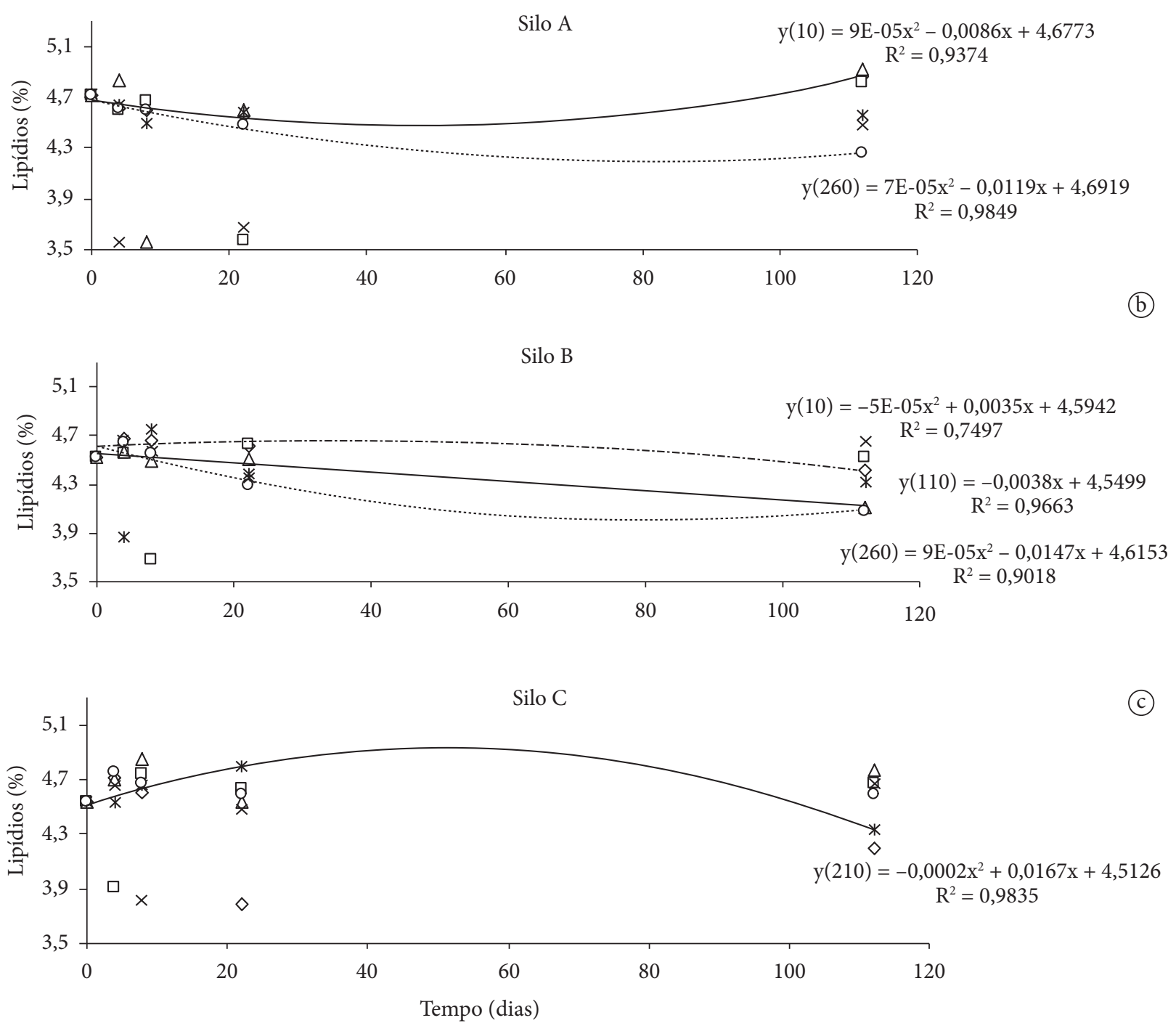

$\diamond 10 \quad \square 60 \quad \Delta 110 \times 160 * 210 \quad \circ 260$

Figura 3. Teor de lipídios de seis alturas de camada (10,60,110, 160, 210 e $260 \mathrm{~cm})$ nos silos A, B e C, contendo grãos de milho colhidos com 20,$5 ; 18,9$ e 17,8\% de água, respectivamente e submetidos à secagem e armazenamento com ar natural forçado. 
altura. A redução do teor de lipídios na altura de camada de $260 \mathrm{~cm}$ foi devido à menor velocidade de secagem em relação às camadas inferiores. Nos silos B e C, este comportamento foi similar apesar da menor umidade inicial de colheita dos grãos de milho.

Os resultados mostraram um declínio no conteúdo de matéria seca nos três silos e nas seis alturas de camada no período de 112 dias de armazenamento (Figura 4). As reduções mais significativas ocorreram nas alturas de camada de $260 \mathrm{~cm}$ de cada silo devido à secagem ter ocorrido de forma mais lenta em relação às camadas inferiores. Isso mostra que os grãos perderam matéria seca devido à respiração e à provável invasão de fungos de armazenamento, sendo mais pronunciada nas camadas superiores.

A umidade de armazenamento do grão depende de sua constituição química. Os grãos com elevado teor de lipídios devem ser armazenados com teor de água mais baixo em relação aos que apresentam elevadas quantidades de proteínas ou amido (BHATTACHARYA; RAHA, 2002). Durante o período de armazenamento, fungos de armazenamento substituem progressivamente os fungos de campo. No teor de água de 15 a $19 \%$ e atividade de água de 0,75 a 0,85, a maioria das espécies de fungos de campo são inibidas ou morrem, enquanto as de fungo de armazenamento crescem lentamente (FLEURAT-LESSARD, 2002).

Os menores conteúdos de matéria seca foram encontrados nas alturas de camada de $260 \mathrm{~cm}$ para as três umidades de colheita. O decréscimo do conteúdo de matéria seca em grãos de milho armazenados por 120 dias está associado principalmente ao aumento da população de fungos de armazenamento que utilizam os nutrientes do grão como fonte de energia (TANAKA et al., 2001).
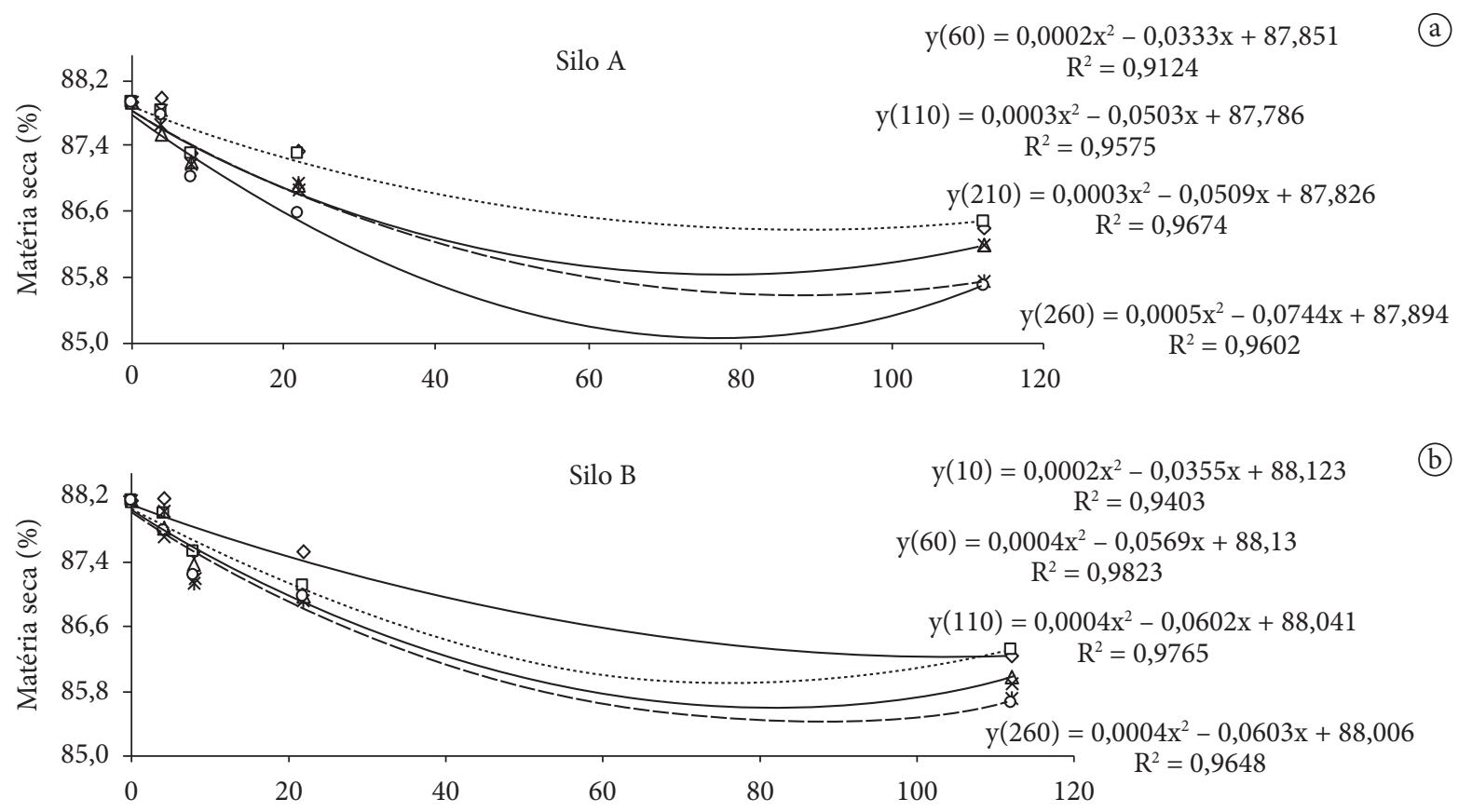

(b)

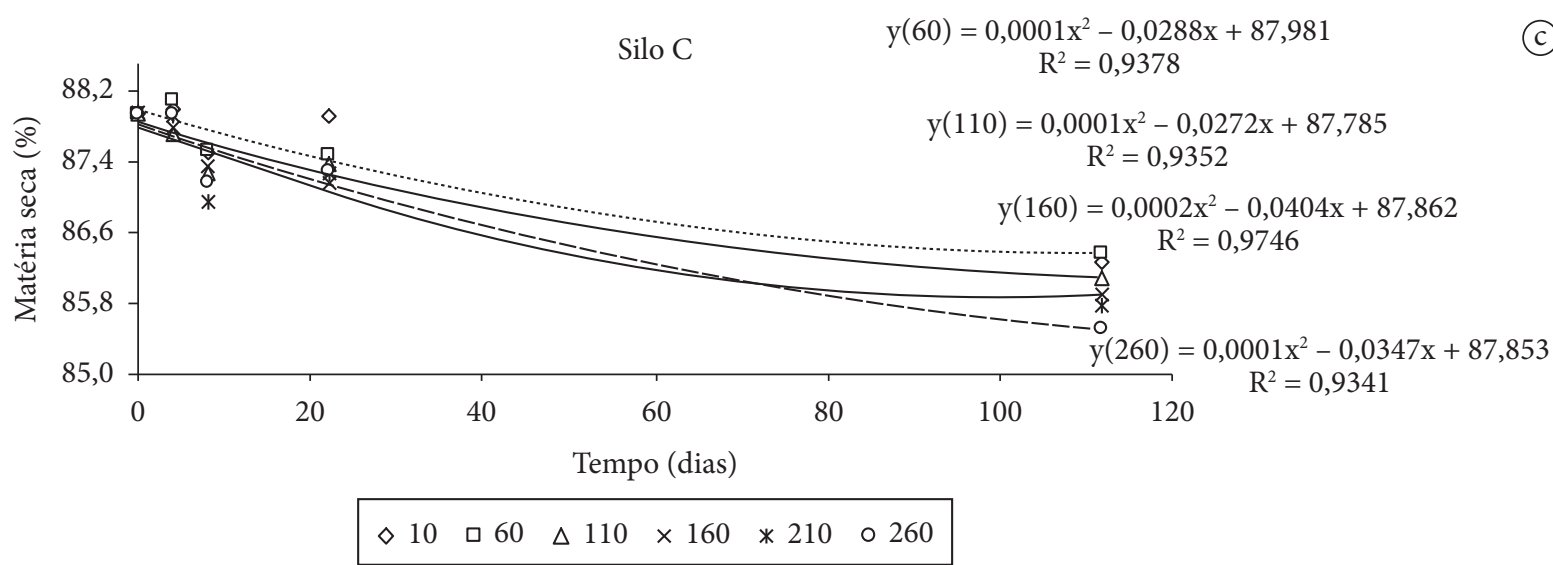

Figura 4. Teor de matéria seca de seis alturas de camada (10,60, 110, 160, 210 e $260 \mathrm{~cm})$ nos silos A, B e C, contendo grãos de milho colhidos com 20,5; 18,9 e 17,8\% de água, respectivamente, e submetidos à secagem e armazenamento com ar natural forçado. 
Bhattacharya e Raha (2002) observaram que o conteúdo total de carboidratos em grãos de milho foi de $74,7 \%$, reduzindo gradualmente para $57 \%$ com 12 meses de armazenamento. O açúcar insolúvel mostrou também uma tendência descendente, passando de 73 a 56\%, enquanto o açúcar solúvel diminuiu de 1,7 para $1,1 \%$.

\section{Conclusões}

A aeração natural forçada é capaz de reduzir a umidade do milho para $13 \%$, sendo tecnicamente viável em propriedades familiares.

As maiores variações dos constituintes químicos do grão, independentemente da umidade de colheita ocorrem na parte superior dos silos.

\section{Agradecimentos}

Ao MCT/CNPq pelo apoio financeiro e bolsas de iniciação científica e produtividade em pesquisa; ao Grupo Fockink pelo apoio financeiro ao projeto.

\section{Referências bibliográficas}

ALVES, W. M. et al. Qualidade dos grãos de milho em função da umidade de colheita e da temperatura de secagem. Revista Brasileira de Engenharia Agrícola e Ambiental, v. 5, n. 3 p. 469-474, 2001.

ASSOCIATION OF OFICIAL ANALYTICAL CHEMISTS - AOAC. Official methods of analysis of AOAC International. $18 \mathrm{ed}$. Gaithersburg: AOAC, 2005.

BHATTACHARYA, K.; RAHA, S. Deteriorative changes of maize, groundnut and soybean seeds by fungi in storage. Mycopathologia, v. 155, n. 3, p 135-141, 2002.

BIAGGIONI, M. A. M.; SOARES, T. A.; FERREIRA, W. A. Variação do índice de acidez graxa, em grãos de milho, segundo diferentes fontes de danificação. Revista Brasileira de Armazenamento, v. 30, n. 2, p. 152-156, 2005.

BIAGI, J. D.; BERTOL, R.; CARNEIRO, M. C. Secagem de grãos para unidades centrais de armazenamento. In: LORINI, I.; MIIKE, L. H.; SCUSSEL, V. M. (Eds.). Armazenagem de grãos. Campinas: Bio Génesis Instituto, 2002. p. 289-307.

BRASIL. Ministério da Agricultura, do Abastecimento e da Reforma Agrária. Regras para análise de sementes. Brasília: DNDV; CLAV, 1992. 365 p.
BROOKER, D. B.; BAKKER-ARKEMA, F. W.; HALL, C. W. Drying and storage of grains and oilseeds. New York: Van Nostrand Reinold, 1992.

CARVALHO, D. C. O. et al. Composição química e energética de amostras de milho submetidas a diferentes temperaturas de secagem e períodos de armazenamento. Revista Brasileira Zootécnica, v. 33, n. 2, p. 358-364, 2004.

DENTI, E. A.; REIS, E. M. Levantamento de fungos associados às podridões do colmo e quantificação de danos em lavouras de milho do planalto médio gaúcho e dos campos gerais do Paraná. Fitopatologia Brasileira, v. 28, n. 6, p. 585-590, 2003.

ELIAS, M. C. et al. Operações de pré-armazenamento, armazenamento e conservação de grãos. In: ELIAS, M. C. (Ed.). Pós-colheita de arroz: secagem, armazenamento e qualidade. Pelotas: UFPel, 2007. p. $147-244$.

FARONI, L. R. D.; DEVILLA, I. A. Tecnologia de aeração e resfriamento de grãos. In: CONFERÊNCIA NACIONAL DE PÓS COLHEITA SAG-MERCOSUL, 2., 2001, Londrina. Anais... Londrina: Fundação de Apoio à Pesquisa e ao Desenvolvimento do Agronegócio, 2001. p. 298-327.

FLEURAT-LESSARD, F. Qualitative reasoning and integrated management of the quality of stored grain: a promising new approach. Journal of Stored Produts Research, v. 38, n. 2, p. 191-218, 2002.

PORTELLA, J. A.; EICHELBERGER, L. Secagem de grãos. Passo Fundo: Embrapa Trigo, 2001.

RODRIGUEZ, J. C. Evaluación de un sistema de secado de granos com aire natural. In: SIMPÓSIO INTERNACIONAL DE CONSERVAÇÃO DE GRÃOS, 1993, Canela. Anais... Canela: CESA; FAO, 1993. p. 215-234.

RUPOLLO, G. et al. Sistemas de armazenamento hermético e convencional na conservabilidade de grãos de aveia. Ciência Rural, v. 34, n. 6, p. 1715-1722, 2004.

SILVA, J. S. Secagem e armazenagem de produtos agrícolas. Viçosa: Aprenda Fácil, 2000.

TANAKA, M. A. S. et al. Microflora fúngica de sementes de milho em ambientes de armazenamento. Scientia Agrícola, v. 58, n. 3, p. 501-508, 2001.

WEBER, F. H.; ELIAS, M. C.; GUTKOSKI, L. C. Estabilização de farinha de aveia da cultivar UPF 18 por tratamento hidrotérmico a vapor. Revista Brasileira de Agrociência, v. 8, n. 3, p. 253- 258, 2002.

ZADERNOWSKI, R.; POLAKOWSKA, H. N.; RASHED, A. A. The influence of heat treatament on the activity of lipo and hidrophilic components of oat grain. Journal of Food Processing and Preservation, v. 23, n. 1, p. 177-191, 1999. 